\title{
Colletotrichum siamense causes anthracnose on the fruits of Pongamia pinnata in India
}

\author{
Dwarka DJ ${ }^{1}$, Sharma G ${ }^{2,3,}$ and Rajasab $\mathrm{AH}^{1}$
}

${ }^{1}$ Mycology and Plant Pathology Laboratory, Department of P.G. Studies and Research in Botany, Gulbarga University, Gulbarga-585106, Karnataka, India

${ }^{2}$ Microbial Type Culture Collection and Gene Bank, CSIR-Institute of Microbial Technology, Sector 39-A, Chandigarh - 160036, India

${ }^{3}$ Department of Plant Pathology and Weed Research, Agriculture Research Organization, The Volcani centre, Bet Dagan - 7528809, Israel

Dwarka DJ, Sharma G, Rajasab AH 2016 - Colletotrichum siamense causes anthracnose on the fruits of Pongamia pinnata in India. Mycosphere 7(4), 492-498, Doi 10.5943/mycosphere/7/4/8

\begin{abstract}
Pongamia pinnata is an economically important biodiesel yielding plant. The growth and yield of this plant is inhibited by infections caused by fungal pathogens. In this study, we investigated the association and pathogenicity potentials of Colletotrichum siamense on fruits of $P$. pinnata collected from Gulbarga University Campus, Karnataka, India. The pathogen was isolated from pericarp (epicarp and endocarp) of $P$. pinnata by blotter and carpoplane method. Fungal characterization and identification was performed based on morphology and multi-locus phylogeny. Pathogenicity testing on $P$. pinnata fruits confirmed the pathogenic potential of the isolate. This is the first report of $C$. siamense as a causative agent of anthracnose on the fruits of $P$. pinnata from Karnataka, India.
\end{abstract}

Key words - Biofuel - disease - germination pattern - identification - morphology - multigene phylogeny

\section{Introduction}

Pongamia pinnata (L.) Pierre is a small evergreen tree species belonging to Fabaceae. This legume tree species is widely distributed in Australia, China, India and Pakistan (Kirtikar et al. 1994). The biofuel obtained from P. pinnata is used as a biodiesel in industries (De \& Bhattacharya 1999, Azam et al. 2005, Karmee \& Chadha 2005). This plant has long been used as a source of animal fodder, fuel, manure, fish poison, timber and traditional medicine for a long time. It is believed that the large scale cultivation of $P$. pinnata would fulfill the demands of biofuel in India (Punia et al. 2006).

Colletotrichum is one of the ten most important phytopathogenic fungal genera (Dean et al. 2012) which causes anthracnose in wide range of host plants, mainly in the tropical and subtropical regions (Sutton 1992, Hyde et al. 2009a, b, Cannon et al. 2012, Damm et al. 2012a, b, Weir et al. 2012). Identification of Colletotrichum species is difficult due to overlapping morphological characters and low genetic divergence within different species complexes (Cannon et al. 2012, Damm et al. 2012a, b, Sharma et al. 2013a, Hyde et al. 2014, Yan et al. 2015). Colletotrichum species can easily adapt to new environmental conditions, thus having the capacity to infect diverse hosts (Sanders \& Korsten 2003, Photita et al. 2004, Yan et al. 2015). It is essential to identify the 
pathogen accurately to apply effective disease control strategies (Hyde et al. 2009 a, b, Hyde et al. 2014, Yan et al. 2015). Since October 2012 till June 2013, it was observed that the fruits and legumes of $P$. pinnata in almost 50\% trees of Gulbarga University Campus (Karnataka, India) displayed anthracnose symptoms. Thus this study was initiated to characterize the pathogenic Colletotrichum species responsible for the anthracnose on fruits of $P$. pinnata, based on morphology, multi-locus sequence analysis and pathogenicity data.

\section{Materials \& Methods}

\section{Fungal isolation and DNA extraction}

Infected (mature, symptomatic) P. pinnata fruit samples were collected from October 2012 till June 2013, at five locations within the Gulbarga University Campus, Gulbarga, Karnataka, India $\left(17.33^{\circ} \mathrm{N} 76.83^{\circ} \mathrm{E}\right)$. Fungal isolation was performed using two methods: moist blotting technique and serial dilution (carpoplane) plate method (Aneja 2008). A total of 20 fungal isolates were obtained, and tentatively identified as Colletotrichum sp. based on morphology. The genomic DNA was isolated for a representative strain (MTCC 11766) using DNA isolation kit (Zymo Research, Catalogue number D6005, California, USA) and stored at $-20{ }^{\circ} \mathrm{C}$ till further processing.

\section{PCR amplification and sequencing of genes}

The representative Colletotrichum strain (MTCC 11766) was subjected to PCR amplification and sequencing of actin (act), calmodulin ( cal), glyceraldehyde-3-phosphate dehydrogenase (gapdh), $\beta$-tubulin (tub2) and internal transcribed spacer region (ITS)/ 5.8S rRNA genes as described in Sharma et al. (2013a). The resulting gene sequences have been submitted to NCBI-GenBank (accession nos. KX068699-KX068704).

\section{Phylogenetic analysis}

The forward and reverse sequences obtained for each gene were aligned using Sequencher v.4.10.1 (Gene Codes Corp., Ann Arbor, Michigan, USA) to generate a consensus sequence. A concatenated multi-locus dataset comprising act, cal, gapdh, tub2 and ITS was generated using Sequence Matrix v.1.7.8 (Vaidya et al. 2011). Maximum parsimony (MP) analysis was performed using PAUP version 4.0b10 (Swofford 2003), as described in (Sharma et al. 2013a).

\section{Morphological characterization}

Mycelial discs (4 $\mathrm{mm}$ diam.) were taken from actively sporulating areas near the growing edge, transferred to potato dextrose agar (PDA) plates, incubated at $28{ }^{\circ} \mathrm{C}$ and investigated after 7 days (Fig. 1a-c, g). The size and shape of 100 conidia harvested from MTCC 11766 were recorded. The colony size, color of the conidial mass and zonation were also recorded. Appressoria were studied using slide culture technique, in which $10 \mathrm{~mm}^{2}$ piece of PDA was placed in an empty Petri dish. The edge of the agar was inoculated with spores taken from a sporulating culture and a sterile cover slip was placed over the inoculated agar (Johnston \& Jones 1997). The shape and size of the appressoria formed across the underside of the cover slip were studied after 3-7 days (Fig. 1d-f).

\section{Growth rate}

A mycelial disc from the actively growing edge of 7 days old culture was transferred onto PDA plates. The culture plates were incubated at $28{ }^{\circ} \mathrm{C}$ under constant fluorescent light. Colony diameter was measured daily for 7 days and growth rate was calculated as the average of growth for 7 days ( $\mathrm{mm} /$ day).

\section{Germination pattern}

The conidial mass from the sporulating culture was taken with the help of sterilized needle and released into sterile distilled water. Conidial suspension of concentration $1 \times 10^{6}$ spores $/ \mathrm{ml}$ was prepared using serial dilution. The conidial suspension was mixed with different concentrations 
$(1 \%, 2 \%, 5 \%$ and $10 \%)$ of sucrose solution and a drop was placed on a cavity slide. The cavity slide was incubated for 4-6 hours in a Petri plate lined with sterilized moist blotting sheet at room temperature. Simultaneously, a sterilized glass slide was coated with a thin layer of PDA medium and placed in Petri plate lined with sterilized moist blotting sheet having glass rods for support. The suspension was sprayed over PDA and incubated for $6-8$ hours at $28{ }^{\circ} \mathrm{C}$ under lab conditions. Ten such Petri plates were set separately and all of them were observed under microscope.

\section{Pathogenicity test}

A representative isolate, MTCC 11766 was used for pathogenicity testing. The spores were harvested from 7 day old pure culture by adding $10 \mathrm{ml}$ of sterilized distilled water onto the Petri plate, followed by gentle swirling. Spore concentration was adjusted to $1 \times 10^{6}$ conidia $/ \mathrm{ml}$ using haemocytometer. Healthy $P$. pinnata fruits were taken from the University campus, disinfected with $1 \%$ sodium hypochlorite for five minutes and washed three times with distilled water. Five fruits were blotted dry and inoculated using $6 \mu \mathrm{l}$ of conidia suspension $\left(10^{6}\right.$ conidia/ml $)$ via wound/drop and non-wound/drop inoculation method (Cai et al. 2009) respectively. Five control fruits were inoculated with $6 \mu \mathrm{l}$ of sterilized distilled water. The inoculated fruits were incubated at room temperature in a moist chamber. The appearances of infection were observed from 4-6 days on incubation (Fig. 1h-i). The pathogenicity assay was repeated thrice.

\section{Results}

\section{Morphological and cultural characterization}

The isolate MTCC 11766 initially produced white colony which later turned grayish (Fig. 1a), and the reverse was pale yellowish to orange (Fig. 1b). Aerial mycelia were grayish white and cottony. The growth rate was recorded as $5.0-12.5 \mathrm{~mm} /$ day (mean $=8 \mathrm{~mm} / \mathrm{day} ; \mathrm{n}=30$ ). Setae were absent. The conidia were cylindrical with smooth wall, obtuse to slightly rounded ends, 9.0-16.0 $\mu \mathrm{m}$ (mean 13.3 $\pm 1.6 \mu \mathrm{m} ; \mathrm{n}=100$ ) in length and 4-7.0 $\mu \mathrm{m}$ (mean 5.7 $\pm 0.7 \mu \mathrm{m} ; \mathrm{n}=100$ ) in width, $\mathrm{L} / \mathrm{W}$ ratio $=2.3$ (Fig. 1c). Sclerotia were present. Appressoria were irregular in shape, brown and ovoid in structure, 5.0-8.0 $\mu \mathrm{m}$ (mean 6.3 $\pm 0.5 \mu \mathrm{m} ; \mathrm{n}=50$ ) in length and 3-5.0 $\mu \mathrm{m}$ (mean 3.7 $\pm 0.3 \mu \mathrm{m}$; $\mathrm{n}=50)$ in width; observed in slide cultures, in all concentration $(1 \%, 2 \%, 5 \%$ and $10 \%)$ of sucrose solutions, and mostly formed from mycelia. The sexual morph was not observed in culture. The morphological characteristics of MTCC 11766 are comparable to the type strain of $C$. siamense MFLU 090230 (Prihastuti et al. 2009).

\section{Phylogenetic analysis}

The multi-locus dataset included 2367 characters, including gaps. The gene boundaries in the dataset included: ITS: 1-601, act: 602-880, cal: 881-1628, gapdh: 1629-1936 and tub2: 19372367. The analysis involved 42 taxa. Seventy-one characters from the ambiguously-aligned regions were excluded from the analysis. Out of the remaining 2296 characters, 1735 characters were constant; 272 characters were parsimony-informative and 289 characters were parsimonyuninformative. The MP analysis resulted in 348 trees and based on the KH test, and these trees were not significantly different (details not shown). One of the 348 trees $(\mathrm{TL}=875, \mathrm{CI}=0.747$, RI $=0.861, \mathrm{RC}=0.644, \mathrm{HI}=0.253$ ) generated from the MP analysis is shown in Fig. 2 . The tree is rooted with $C$. xanthorrhoeae ICMP 17903. The bootstrap support values higher than $50 \%$ for the observed branches are shown. In the MP tree shown in Fig. 2, the isolate MTCC 11766 clustered with the ex-type strains of $C$. siamense sensu stricto with $60 \%$ bootstrap support.

\section{Germination pattern}

Conidia of MTCC 11766 were readily germinated within 12 hours of incubation at $28{ }^{\circ} \mathrm{C}$ under lab conditions. During first 6 hours of incubation, the conidial germination was absent. After 6-10 hours incubation, 6-8\% of conidia germinated with budding on both ends. The germination was observed in all the concentrations of sucrose. Conidia bud-off and produced one or two germ 
tube to form mycelia and appressoria. Appressorial formation generally started after 12 hours of incubation. The appressoria were also formed from the mycelia (Fig. 1d-f). Some conidia produced a single germ tube at terminal or sub-terminal portion and later branched further. A few conidia produced germ tubes with horizontal or lateral branches. Generally, at $25-30^{\circ} \mathrm{C}$, the percentage of conidial germination in Colletotrichum is highest and almost reaches $100 \%$ within 6 hours (Estrada et al. 2000).However, in our study, during first 6 hours of incubation the germination was absent. The germination started only after 6 hours of incubation and reached 6-10\% after 12 hours.

\section{Pathogenicity test}

The Pongamia fruits inoculated with conidial suspension of strain MTCC 11766 developed typical anthracnose lesions (Fig. 1h), while the control fruits did not develop any symptoms (Fig. 1i). The inoculated pathogen was isolated again from the infected fruits on to the PDA medium to confirm Koch's postulates. With the wound/drop inoculation method, lesions appeared after 3 days of inoculation (Fig. 1h), while non/wound drop inoculation, lesions appeared after 7 days of inoculation. The identity of the pathogen isolated from artificially inoculated fruits was verified again by sequencing and morphology.
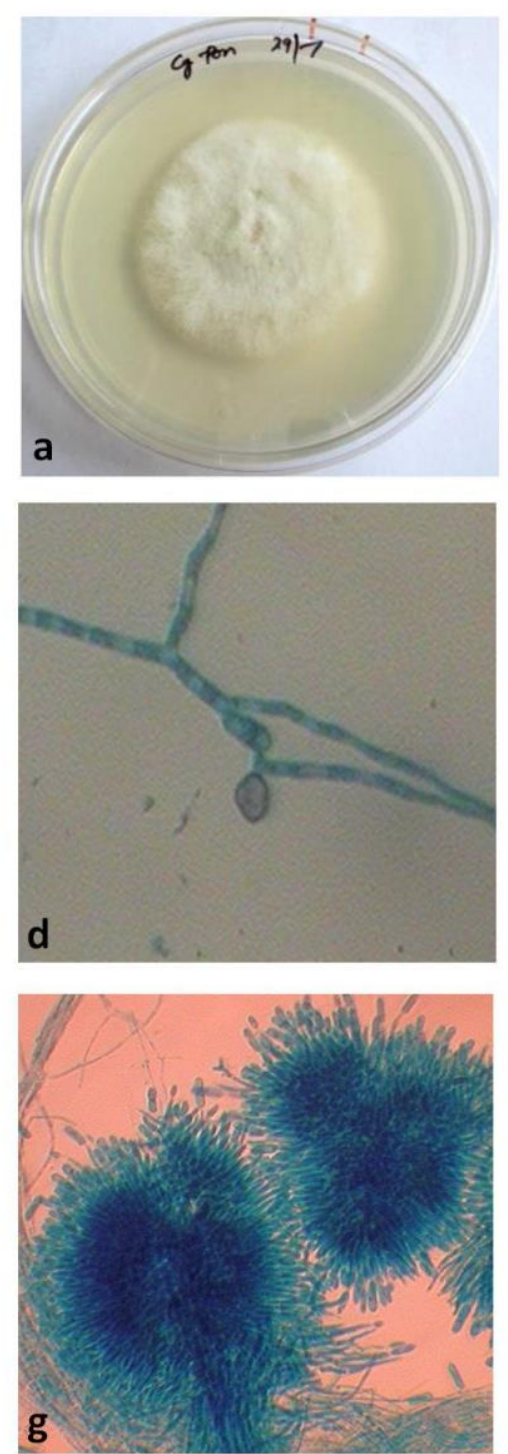
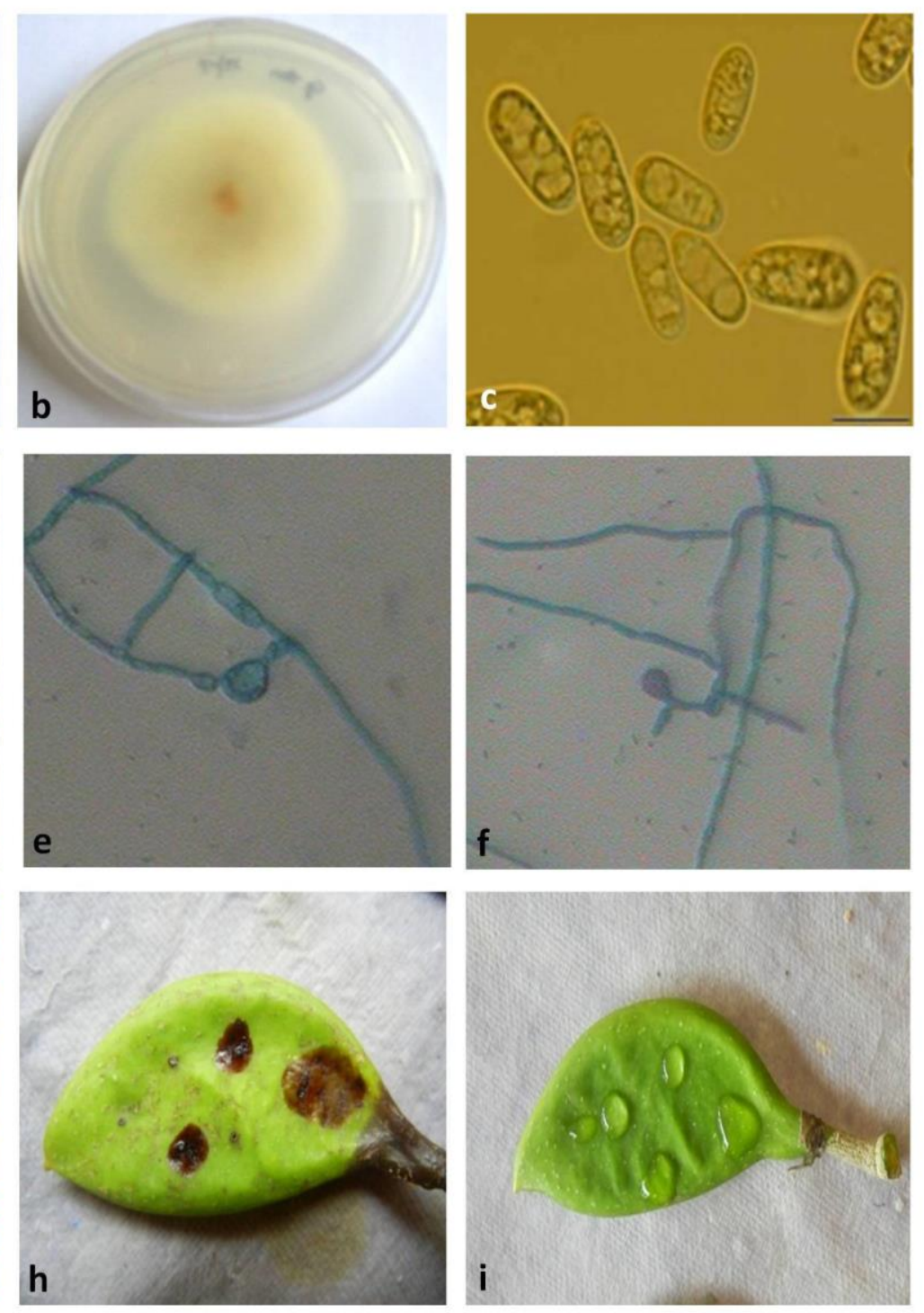

Fig. 1 - a. Colony morphology on PDA (front), b. Colony morphology on PDA (reverse), c. Conidia (Scale bar $=10 \mu \mathrm{m}$ ), d-f. Appressoria, $\mathbf{g}$. Conidiogenous cells, $\mathbf{h}$. Infection symptoms on $P$. pinnata fruits after 5 days of inoculation, i. control fruit 


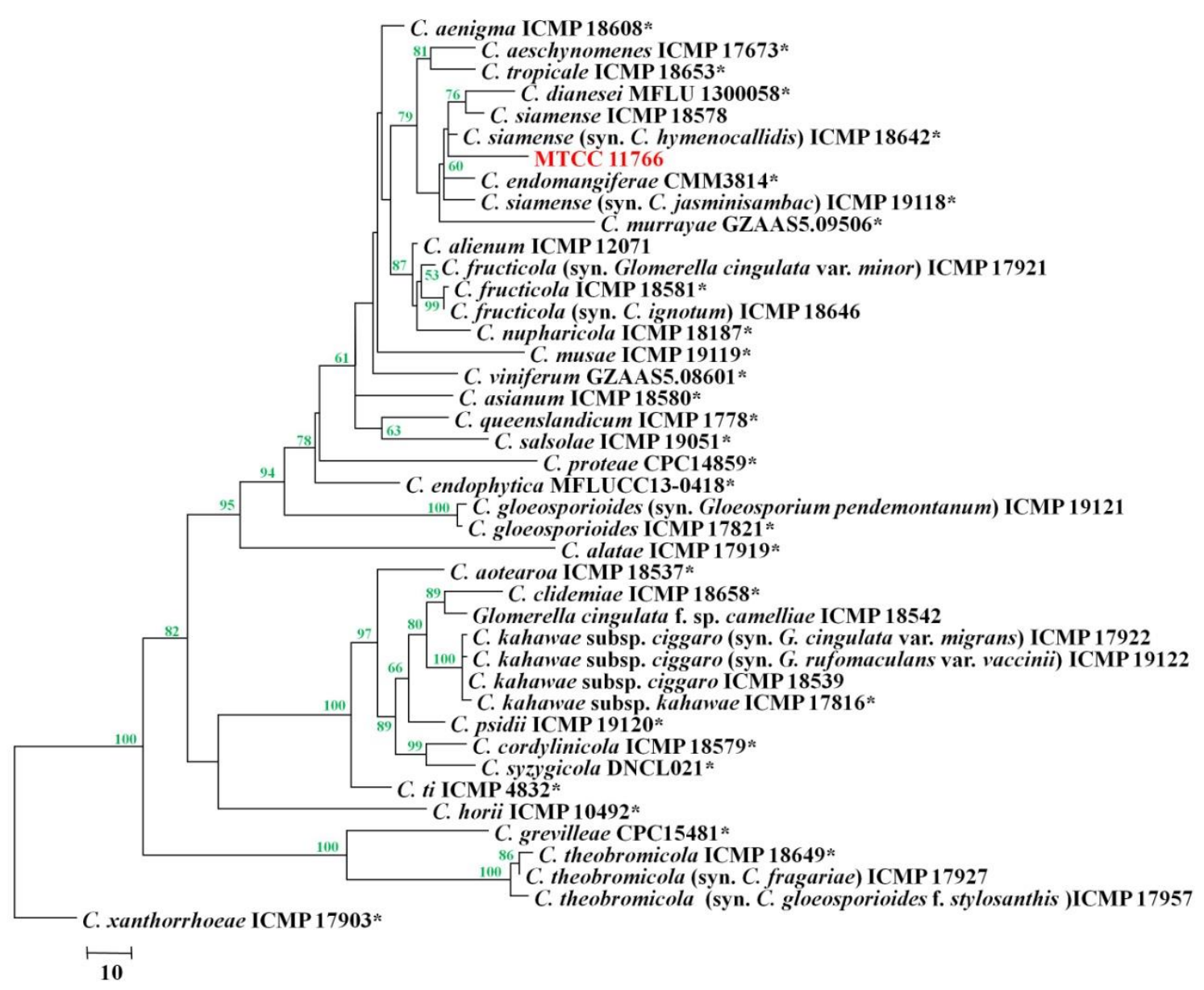

Fig. 2 - One of the 348 most parsimonious trees showing phylogenetic affinities of Colletotrichum isolate MTCC 11766 from India (highlighted in red). Colletotrichum xanthorrhoeae strain ICMP 17903 is the designated outgroup, and bootstrap support values higher than $50 \%$ are shown at the nodes. Ex-type strains are marked with an asterisk.

\section{Discussion}

In developing countries such as India, there is an increasing demand for fuel to meet everyday transportation needs. Concurrently, there is a gradual and frequent hike in the cost of fossil fuel in the international market. To minimize the import of crude oil, there is a need to increase the usage of renewable and eco-friendly biofuels. Pongamia pinnata is one of the promising candidates for bio-diesel production which are renewable, safe, non-polluting and ecofriendly. The seeds of $P$. pinnata contain around 30-40\% of oil which has been used as a source of biofuel (Azam et al. 2005, Karmee \& Chadha 2005). Various fungal species can infect $P$. pinnata fruits and seeds, on tree and during storage; which affects seed germination and oil production (Arya et al. 2015). This may threat the growth of this plant in fields and cause severe yield loss. So far, there have been limited anthracnose reports from this plant worldwide (Farr and Rossman 2016). In this study, $C$. siamense has been identified from the diseased fruits of $P$. pinnata on the basis of morphological characters, multi-locus phylogeny and pathogenicity test. The development of disease symptoms was faster ( 3 days) via wound inoculation as compared to non-wound inoculation (5-7 days). In addition, the germination pattern of the conidia was also investigated. Interestingly, no spore-germination was observed after first 6 hours of incubation, as opposed to previous report by Estrada et al. (2000). Germination of spores was initiated only after 6 hours of incubation, inferring that the rate of germination of the pathogen is less on fruits. More studies are required to obtain insights into germination rate of the pathogen on leaves and shoot. 
Colletotrichum siamense was first described as a pathogen associated with anthracnose of coffee berries (Prihastuti et al. 2009) in northern Thailand. This species has been so far reported from various hosts such as apple, chilli, coffee, jasmine, mango, papaya and strawberry (Phoulivong et al. 2010, Weir et al. 2012, Sharma et al. $2013 \mathrm{a}$, b). It is also a dominant species on tropical fruits (Sharma et al. 2013a, Udayanga et al. 2013). The status of $C$. siamense as a species was under debate. Some of the research articles hint at the presence of cryptic species within $C$. siamense (Sharma et al. 2013a, 2015, Udayanga et al. 2013, Vieira et al. 2014), whereas a recent study by Liu et al. (2016) characterized $C$. siamense as a single species based on statistical analysis using multi-locus sequence data, as well as cross-mating and genetic recombination tests. Thus, in this report we have followed the recent approach by Liu et al. (2016) to avoid further confusion, and used the name "Colletotrichum siamense". This is the first report of $C$. siamense as a causative agent of anthracnose on the fruits of $P$. pinnata from Karnataka, India. This information of host and pathogen will be useful to plant pathologists to design disease control strategies for $P$. pinnata. Pongamia pinnata is a perennial plant; thus by inhibiting pathogens, healthy plants can be cultivated round the year and sufficient fuel and fodder can be obtained for the cattle.

\section{Acknowledgements}

DDJ thanks University of Gulbarga for Ph. D. fellowship. GS thanks Council of Scientific and Industrial Research, India and Planning and Budget Committee, Israel for research fellowship.

\section{References}

Aneja KR. 2008 - Experiments in microbiology plant pathology and biotechnology. New Age Interntional publishers.

Arya P, Tiwari SC, Pandey A. 2015 - Evaluation of different chemical fungicides and microbial antagonists to control storage mycoflora of Pongamia pinnata seeds. International Journal of Life Sciences 4, 154-163.

Azam MM, Waris, Nahar NM. 2005 - Prospects and potential of fatty acid methyl esters of some nontraditional seed oils for use as biodiesel in India. Biomass and Bioenergy 29, 293-302.

Cai L, Hyde KD, Taylor PWJ, Weir BS, Waller J, Abang MM, Zhang JZ, Yang YL, Phoulivong S, Liu ZY, Prihastuti H, Shivas RG, McKenzie EHC, Johnston PR. 2009 - A polyphasic approach for studying Colletotrichum. Fungal Diversity 39, 183-204.

Cannon PF, Damm U, Johnston PR, Weir BS. 2012 - Colletotrichum - current status and future directions. Studies in Mycology 73, 181-213.

Damm U, Cannon PF, Woudenberg JHC, Crous PW. 2012b - The Colletotrichum acutatum species complex. Studies in Mycology 73, 37-113.

Damm U, Cannon PF, Woudenberg JHC, Johnston PR, Weir BS, Tan YP, Shivas RG, Crous PW. 2012a - The Colletotrichum boninense species complex. Studies in Mycology 73, 1-36.

De BK, Bhattacharya DK. 1999 - Biodiesel from minor vegetable oils like karanja oil and nahor oil. Lipid/Fett. 101, 404-406.

Dean R, Van Kan JAL, Pretorius ZA, Hammond-Kosack KE, Pietro AE, Spanu PD, Rudd JJ, Dickman M, Kahmann R, Ellis J, Foster JD. 2012 - The top 10 fungal pathogens in molecular plant pathology. Molecular Plant Pathology 13, 414-430.

Estrada AB, Dodd JC, Jeffries P. 2000 - Effect of humidity and temperature on conidial germination and appressorium development of two Philippine isolates of the mango anthracnose pathogen Colletotrichum gloeosporioides. Plant Pathology 49, 608-618.

Farr DF, Rossman AY. 2016 - Fungal Databases, Systematic Mycology and Microbiology Laboratory, ARS, USDA. http://nt.ars-grin.gov/fungaldatabases/ (accessed 10 June 2016)

Hyde KD, Cai L, Cannon PF, Crouch JA, Crous PW, Damm U, Goodwin PH, Chen H, Johnston PR, Jones EBG, Liu ZY, McKenzie EHC, Moriwaki J, Noireung P , Pennycook SR, Pfenning LH, Prihastuti H, Sato T, Shivas RG, Tan YP, Taylor PWJ, Weir BS, Yang Y, Zhang JZ. 2009b - Colletotrichum: names in current use. Fungal Diversity 39, 147-182. 
Hyde KD, Cai L, McKenzie EHC, Yang YL, Zhang JZ, Prihastuti H. 2009a - Colletotrichum: a catalogue of confusion. Fungal Diversity 39, 1-17.

Hyde KD, Nilsson RH, Alias SA, Ariyawansa HA, Blair JE, Cai L, de Cock AWAM, Dissanayake AJ, Glockling SL, Goonasekara ID, Gorczak M, Hahn M, Jayawardena RS, van Kan JAL, Laurence MH, Lévesque CA, Li XH, Liu JK, Maharachchikumbura SSN, Manamgoda DS, Martin FN, McKenzie EHC, McTaggart AR, Mortimer PE, Nair PVR, Pawłowska J, Rintoul TL, Shivas RG, Spies CFJ, Summerell BA, Taylor PWJ, Terhem RB, Udayanga D, Vaghefi N, Walther G, Wilk M, Wrzosek M, Xu JC, Yan JY, Zhou N. 2014 - One stop shop: backbones trees for important phytopathogenic genera: I. Fungal Diversity 67, 21-125.

Johnston PR, Jones D. 1997 - Relationships among Colletotrichum isolates from fruit-rots assessed using rDNA sequences. Mycologia 89, 420-430.

Karmee SJ, Chadha A. 2005 - Preparation of biodiesel from crude oil of Pongamia pinnata. Bioresource Technology 96, 1425-1429.

Kirtikar KR, Basu BD. 1994 - Indian medicinal plants. Vol. 1. Dehradun publishers India. pp 830832.

Liu F, Wang M, Damm U, Crous PW, Cai L. 2016 - Species boundaries in plant pathogenic fungi: a Colletotrichum case study. BMC Evolutionary Biology 16, 81-95.

Photita W, Lumyong S, Lumyong P, McKenzie EHC, Hyde KD. 2004 - Are some endophytes of Musa acuminata latent pathogens? Fungal Diversity 16, 131-140.

Phoulivong S, Cai L, Chen H, McKenzie EHC, Abdelsalam K, Chukeatirote E, Hyde KD. 2010 Colletotrichum gloeosporioides is not a common pathogen on tropical fruits. Fungal Diversity 44, 33-43.

Prihastuti H, Cai L, Chen H, McKenzie EHC, Hyde KD. 2009 - Characterization of Colletotrichum species associated with coffee berries in northern Thailand. Fungal Diversity 39, 89-109.

Punia MS, Kureel RS, Pandy A. 2006 - Status and potential of tree borne oil seeds (TBO'S) in biofuel production of India. Indian Journal of Agroforestry 8, 80-86.

Sanders GM, Korsten L. 2003 - A comparative morphology of South African avocado and mango isolates of Colletotrichum gloeosporioides. Canadian Journal of Botany 81, 877-885.

Sharma G, Kumar N, Weir BS, Hyde KD, Shenoy, BD. 2013a - Apmat gene marker can resolve Colletotrichum species: a case study with Mangifera indica. Fungal Diversity 61, 117-138.

Sharma G, Pinnaka AK, Shenoy BD. 2015 - Resolving the Colletotrichum siamense species complex using ApMat marker. Fungal Diversity 71, 247-264.

Sharma G, Shenoy BD. 2013b - Colletotrichum fructicola and C. siamense are involved in chilli anthracnose in India. Archives of Phytopathology and Plant protection 47, 1179-1194.

Sutton BC. 1992 - The genus Glomerella and its anamorph Colletotrichum. In: Colletotrichum: biology, pathology and control (eds. J.A. Bailey and M.J. Jeger). CAB International, Wallingford. pp 1-26.

Swofford DL. 2003 - PAUP*. Phylogenetic analysis using parsimony (*and other methods). Version 4. - Sinauer Associates, Sunderland, Massachusetts.

Udayanga D, Manamgoda DS, Liu X, Chukeatirote E, Hyde KD. - 2013. What are the common anthracnose pathogens of tropical fruits? Fungal Diversity 61, 165-179.

Vaidya G, Lohman DJ, Meier R. 2011 - Sequence matrix: concatenation software for the fast assembly of multi-gene datasets with character set and codon information. Cladistics 27, 171-180.

Vieira WAS, Michereff SJ, de Morais Jr MA, Hyde KD, Câmara MPS. 2015 - Endophytic species of Colletotrichum associated with mango in northeastern Brazil. Fungal Diversity 67, 181202.

Weir BS, Johnston PR, Damm U. 2012 - The Colletotrichum gloeosporioides species complex. Studies in Mycology 73, 115-180.

Yan JY, Jayawardena MMRS, Goonasekara DI, Wang Y, Zhang W, Liu M, Huang JB, Wang ZY, Shang JJ, Peng YL, Bahkali A, Hyde KD, Li XH. 2015 - Diverse species of Colletotrichum associated with grapevine anthracnose in China. Fungal Diversity 71, 233-246. 